will not be rubber-stamped any more."

Many scientists, however, accept that some proposals will be turned down on ethical grounds. But they want to know quickly, so they can move on to other projects. The main reason for the delays, they argue, is that the number of officials has failed to keep pace with the burgeoning paperwork.

Some universities are hiring staff to cope with the local review. But the Home Office has only 21 inspectors to oversee the entire regulatory system. "You must cater for the changes by increasing the number of inspectors," says the veterinary researcher.

Some animal-welfare groups agree. The Fund for the Replacement of Animals in Medical Experiments, based in Nottingham, says inspectors turn round applications as quickly as they can - but their workloads are simply too high, and are likely to increase.

Over the past 25 years, the number of experimental procedures involving animals in Britain has decreased steadily. But last year, the total rose by 1 per cent, largely due to a growth in demand for transgenic mice.

As more researchers turn to transgenic mice, this trend is likely to increase. RDS director Mark Matfield predicts that the rising demand for transgenics could push up the total number of animal procedures in Britain by 5 per cent a year. This will be embarrassing for the government, which is committed to reducing the number of animals used for research.

"We are planning to review the ethical review procedure," says a Home Office spokesman. "We are aware of concerns expressed, but we remain convinced that it has a positive role to play." Natasha Loder

\title{
Varmus tells Congress to grasp thorny policy issues
}

Washington

Former director of the National Institutes of Health, Harold Varmus, returned to Washington briefly last week to tell a group of congressmen that they should spend more time addressing the broad political issues that affect biomedical research — and less time seeking budget increases for popular medical causes.

High on the agenda of those interested in promoting such research, he suggested, should be the 'commodifaction' of databases - a reference to the activities of companies that generate and repackage scientific data and sell it to subscribers.

Varmus was addressing the tenth anniversary celebrations of the US Congres-

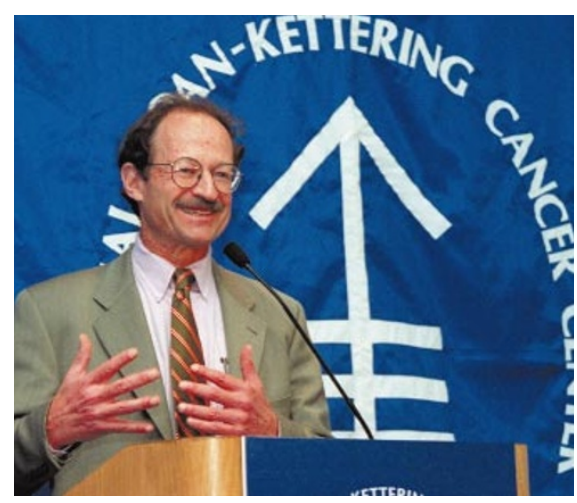

Varmus: wants caucus to reassess priorities. sional Biomedical Caucus. Partly as a result of the success of the caucus, the NIH has received 15 per cent budget increases in each of the past two years, and congressional leaders are pushing for a third such rise.

But Varmus, who left the NIH to become president of the Memorial Sloan-Kettering Cancer Research Center this year, is worried that there may be an imbalance in priorities. "We should take the issues on when they are hot," he said. Issues that the caucus should address include the sale of human genetic information, lapses in overseeing clinical research, and the growth of online research literature, he said.

In its recent activities, the caucus has preferred to focus on less contentious problems, such as the need to combat cystic fibrosis. The failure to discuss more controversial issues leads to misunderstandings when they inevitably arise, Varmus said. He predicted, for example, that the availability of data will become an increasing problem as genomics becomes a bigger business. "Sets of data have become commodities," he said. "This is going to affect the relationship between public and private sectors."

But despite Varmus's urgings, members of the caucus seemed more comfortable repeating conventional concerns, and confirming their belief that the main role of the caucus is to generate enthusiasm for science funding.

Paul Smaglik

\section{US geneticists encouraged to play by the book}

\section{Washington}

US geneticists were warned last week by their professional body that they could be endangering their research if they ignore government regulations protecting the families of subjects involved in human genetics studies.

But the American Society of Human Genetics (ASHG) also suggested that researchers should learn to make use of waivers, or face the "enormously cumbersome and prohibitive" task of enrolling family members as human subjects, a burden that would "seriously impede medical research".

In an alert sent out to its 6,700 members, the society drew attention to a recent case that led to the closure of federally funded research at Virginia Commonwealth University (VCU) in Richmond. The father of college-age twins had complained that a questionnaire sent to his daughter by a university geneticist invaded his privacy by asking hundreds of questions about his own physical and emotional health (see Nature 404, 114-115; 2000).

The Office for Protection from Research Risks (OPRR) of the National Institutes of Health ruled that the university's ethics board should have required the researcher to obtain informed consent not only from recipients of the questionnaire, but also from members of their families.

The alternative, said the OPRR, was that the ethics board should have formally waived this requirement by agreeing that the research posed minimal risk to the rights of other family members and could not be practicably carried out without the waiver.

The ASHG alert was posted by the society's immediate past president, Uta Francke, a professor of genetics at Stanford University. She says that before the VCU case she "didn't know a thing" about the federal regulations covering the collection of information about family members of human subjects, and assumed that many geneticists were equally ignorant. "To prevent any [incidents similar to the VCU case] in the future, our members need to be aware that these regulations exist," she says.

The society's approach contrasts with the more critical stance of Francis Collins, the director of the National Human Genome Research Institute, who challenged the OPRR's application of federal rules at VCU, declaring his “deep concern" about its possible implications for genetics research.

The ASHG alert, in contrast, appears to embrace the ruling, declaring that "there are clear lessons to be learned" from it. In particular, it stresses that geneticists should know the conditions required for ethics boards to grant waivers of informed consent from family members. Meredith Wadman 